\title{
Prospective long-term study of patency and outcomes of 505 arteriovenous fistulas in patients with chronic renal failure: Authors experience and review of literature
}

\author{
Parag Sahasrabudhe, Tushar Dighe1, Nikhil Panse², Shraddha Deshpande, Amit Jadhav, \\ Sheetal Londhe \\ Departments of Plastic Surgery and ${ }^{1}$ Nephrology Deenanath Mangeshkar Hospital, ${ }^{2}$ Department of Plastic Surgery, \\ Sassoon Hospitals, Pune, Maharashtra, India
}

Address for correspondence: Prof. Parag Sahasrabudhe, Plot 82, Lane 2, Natraj Society, Karve Nagar, Pune - 411052 , Maharashtra, India. E-mail: drparags@gmail.com

\section{ABSTRACT}

Background: This study describes our experience of arteriovenous fistula (AVF) creation as vascular access for haemodialysis. Materials and Methods: This study has been carried out in our hospital from January 2004 to December 2012. A total of 505 AVFs were created in 443 patients. Maximum follow-up was 8 years, and minimum was 6 months. Observations and Results: In this study of 505 cases of AVFs, primary patency rates by Kaplan - Meier analysis showed $78.81 \%$ patency of fistulas at the end of 1 year and patency dropped to $14.81 \%$ at the end of 5 years. Our primary failure rate was $21.2 \%$. Basilic vein was used in $26.35 \%$ cases, cephalic vein in $63.5 \%$, and antecubital vein in $9.75 \%$ cases. On table, bruit was present in 459 (90.9\%) and thrill in $451(89.3 \%)$ cases. During dialysis, flow rate $>250 \mathrm{ml} / \mathrm{min}$ was obtained in $150(29.9 \%)$ cases. In complications, $2(0.4 \%)$ patients developed distal oedema, $33(6.5 \%)$ developed steal phenomenon. Conclusions: Presence of on table thrill and bruit are indicators of successful AVF. If vein diameter is $<2 \mathrm{~mm}$, chances of AVF failure are high. Flow rates in patients with vein diam. $>2 \mathrm{~mm}$ were significantly higher as compared with patients with vein diam. $<2 \mathrm{~mm}(P<0.001)$. Flow rates are higher in non-diabetic patients as compared to diabetic patients $(P<0.001)$. Average blood urea and serum creatinine values are significantly lesser in patients undergoing dialysis through successful fistulas as compared to patients with failed fistulas. Correspondingly, incidence of deaths is significantly lesser in patients with successful fistulas. During proximal side-to-side fistula between antecubital/ basilic vein and brachial artery, dilating of the first valve toward wrist helps to develop distal veins in the forearm by retrograde flow. This technique avoids requirement of superficialization of basilic vein in the arm.

\section{KEY WORDS}

Arteriovenous fistula; chronic kidney disease; haemodialysis; vascular access

\begin{tabular}{|l|l|}
\hline \multicolumn{2}{|c|}{ Access this article online } \\
\hline Quick Response Code: & Website: \\
\hline ⿴囗十 & www.ijps.org \\
\cline { 2 - 2 } & \\
\hline
\end{tabular}

\section{INTRODUCTION}

nd stage renal disease (ESRD) patients depend on
lifelong renal replacement therapy (dialysis or renal
transplant) to sustain their lives. After Scribner's
shunt in 1960, Brescia et al. described the creation of
subcutaneous arteriovenous fistula (AVF) constructed 
between the radial artery and an adjacent vein in 1966. Cimino fistulas are currently accepted as the best mode of vascular access for haemodialysis (HD). ${ }^{[1]}$

This is single-centre, single surgeon observational study comparing pre-operative vein and artery diameters, presence of bruit and thrill on operation table, flow rates, site of the fistula, associated comorbidities for postoperative outcome, and duration of patency by Kaplan-Meier analysis.

\section{MATERIALS AND METHODS}

This observation study was carried out in our institute in patients who underwent surgical AVF creation between January 2004 and December 2012.

Patients were advised surgery for AVF when their Modified Diet for Renal Disease estimated Glomerular Filtration Rate ${ }^{[2]}$ was below $15 \mathrm{ml} / \mathrm{min}$. HD catheter was inserted only in cases who presented late and required HD before maturation of fistula.

History of diabetes mellitus, anticoagulant therapy for coagulation disorder, cardiovascular disease, heart valve disease or prosthesis, previous dialysis access, previous central venous, or peripheral catheter were noted. Physical exam of the arterial system (peripheral pulses, Allen test, and bilateral upper extremity blood pressure) was performed along with physical exam of the venous system (tourniquet venous palpation with vein mapping, examination for previous central or peripheral venous catheters, etc.). Dominance of hand was examined, and preference was given to non-dominant hand for creation of vascular access.

Pre-operative colour Doppler ultrasound (duplex) of upper limb veins and arteries was done in selected patients to look for size and patency. It was done in patients with inadequate clinical examination findings like in cases with obesity, absent or feeble pulses, multiple previous access surgeries, indwelling dialysis catheter on the same side, and history suggestive of thrombophlebitis.

Subclavian vein catheterization was avoided for temporary access in all patients due to the risk of central venous stenosis, which compromises entire ipsilateral arm for vascular access. Arm veins suitable for vascular access placement were preserved, and patients and dialysis staff were instructed not to prick selected arm.
In cases where there was extensive venous thrombosis in a particular limb different limb was selected for fistula.

During this period, AVF was created in 756 patients; but, we could follow-up only 443 patients. Follow-up was obtained in collaboration with dialysis unit staff by telephonic calls and personal visits to the patients. The data extracted from hospital records included patient demographics, comorbidities, details of previous access, location and type of AVF, operative details, patency, morbidity, and mortality.

A total of $505 \mathrm{AVFs}$ were placed in 443 patients as 62 patients required repeat procedure due to failure of the previous fistula. Of the 443 patients 187 (42.2\%) patients have died. Average mean survival in dead patients was 1.59 (standard deviation \pm 1.07 ) years. However, before death they were regularly followed-up on dialysis. Maximum follow-up was 8 years, and minimum follow-up was 6 months.

\section{Surgical technique}

All patients were admitted on the day of surgery. All cases were done under local anaesthesia using 10 cc $2 \%$ Xylocaine by single surgeon under loupe magnification using microvascular instruments. "S" shape $2.5-3 \mathrm{~cm}$ long incision was used. Vein and artery were mobilized adequately. Arteriotomy size in all cases was 6-7 mm. In cases wherein there was extensive atherosclerosis involving the artery best possible segment of exposed artery was selected for anastomosis. Diameter of the vessels were noted using calipre. Anastomosis was done by taking continuous running suture using 7-0 polypropylene or 8-0 ethilon depending upon vessel wall thickness. For distal and mid forearm fistula, end of the cephalic vein to side of radial artery anastomosis was performed [Figure 1].

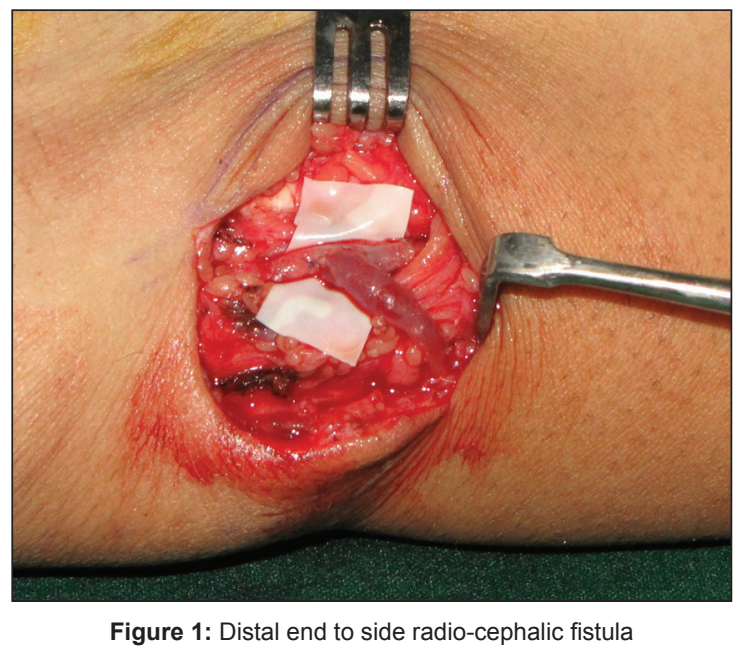


For proximal fistula, we performed side - to-side anastomosis between antecubital or basilic vein and brachial artery [Figure 2]. Before anastomosis was completed, we dilated distal vein using venous dilator to break the first valve toward the wrist end to allow retrograde flow into forearm veins [Figures 3 and 4]. This allows forearms veins to develop [Figure 5] which can now be easily assessed for cannulation. This technique avoided requirement of basilic vein transposition in the arm thus avoiding long incisions in arm and reducing morbidity of the procedure. In cases where antecubital vein was used, both cephalic and basilic veins got arterialized and could be cannulated. Skin closure was done with 3-0 ethilon in a single layer. Non-compressive dressing was given. Bruit was heard, and thrill was felt on operation table end of dressing. In cases where bruit and/ or thrill was absent, but there was good venous filling, we started anticoagulation with low molecular weight heparin subcutaneously for 3-5 days, (doses according to creatinine clearance), along with tablet aspirin $75 \mathrm{mg}$ once a day for 3-5 days.

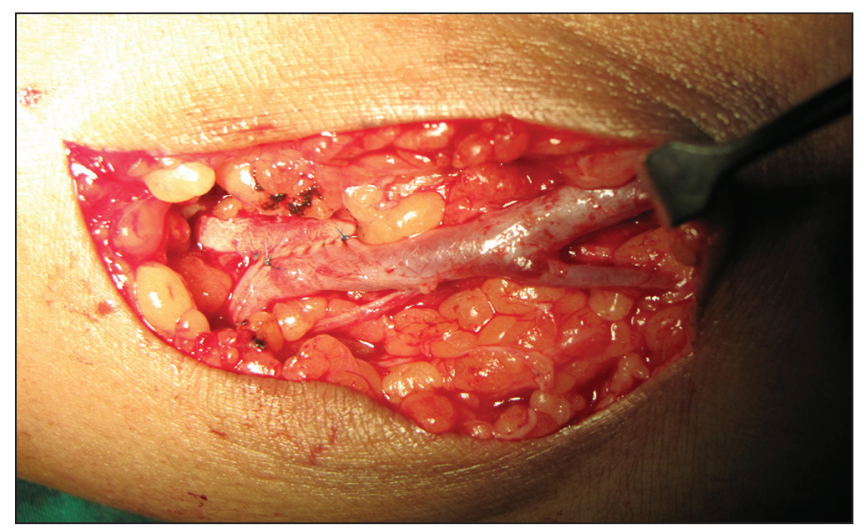

Figure 2: Proximal side-to-side brachiobasilic fistula

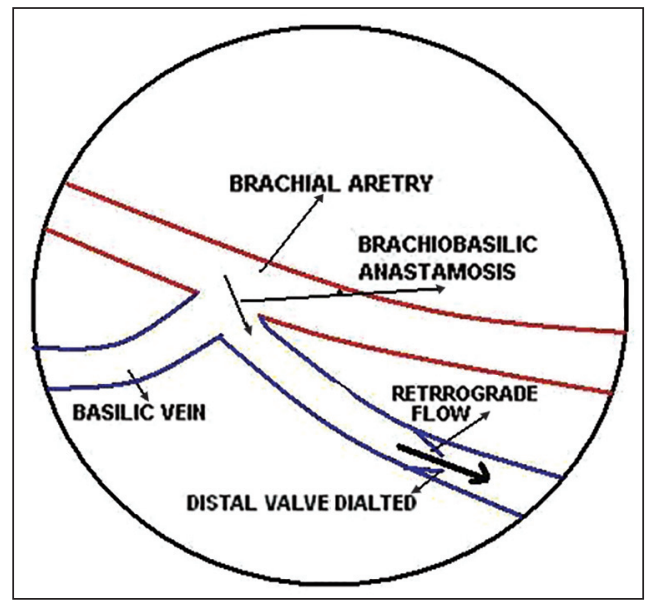

Figure 4: Diagrammatic representation of retrograde flow across dilated valve
Patient was discharged on the same day or next day. Relevant instructions about care of operated side arm were given to the patients and their relatives. They were told to avoid arm vein blood collection on the operated side, avoid blood pressure cuffs, not to use tight clothing or jewellery, and avoid the prolong pressure on operated arm. Written instructions about how to feel for the thrill were given, and patients were asked to report any coldness, numbness, ulcers, discoloration at fingertips. Handball exercises were taught to patients before discharge.

Fistula maturation and its cannulation for use of dialysis were decided by nephrologists based on visible enlarged vein and well felt thrill, which required 4-6 weeks after construction. We considered $250 \mathrm{ml} / \mathrm{min}$ as a flow rate obtained on HD machine during HD, which was sustained for a minimum of $3 \mathrm{~h}$ without recirculation as acceptable flow during HD.

We followed the National Kidney Foundation/Disease Outcome Quality Initiative (NKF-K/DOQI) Vascular

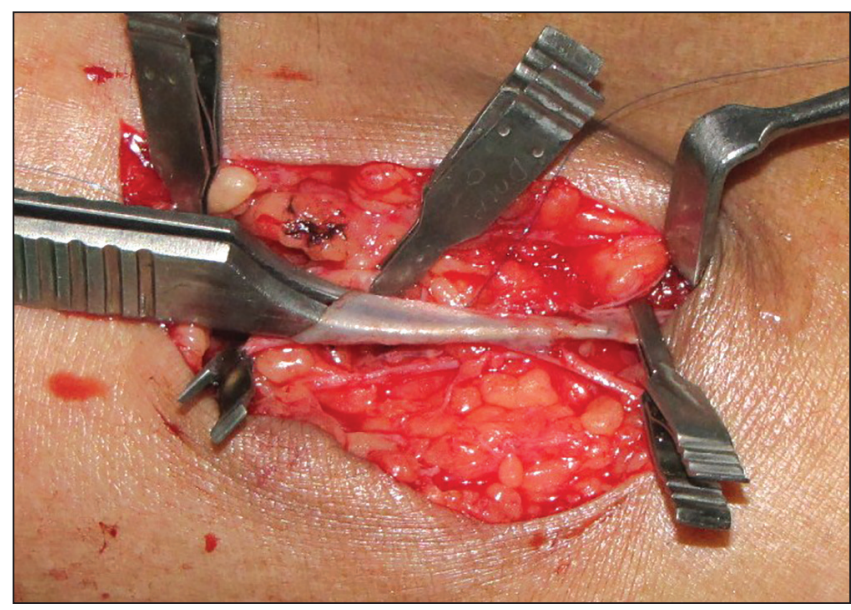

Figure 3: Vessel dilator passed through venotomy to dilate first valve towards wrist end

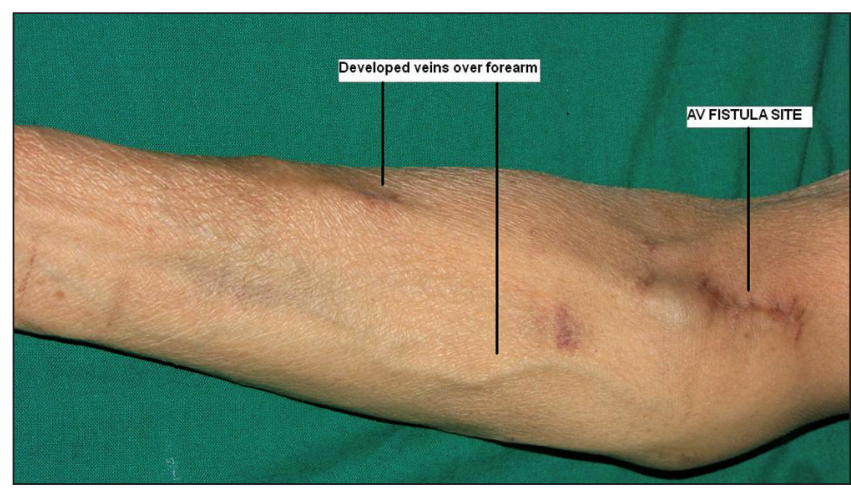

Figure 5: Well-developed forearm veins in proximal arteriovenous fistula 
Access Clinical Practice Guidelines 2000.[3] However, few guidelines could not be followed, for example, early reference, timing of access placement (1-4 months before anticipated HD), Doppler ultrasound in all cases and early intervention in failing fistulas. Above limitations were due to poor patient compliance and affordability in Indian scenario. In none of our patients and interventional or salvage procedure was done. Hence, our patency statistics is of $100 \%$ primary patency rates.

The data were analysed using IBM SPSS (statistical package for social sciences) version 20. Student's $t$-test was used to find the differences. Paired $t$-test is not appropriate in our series as it is for pre- and postcomparison. Chi-square test was used to look at the association.

Regression was used to find predictors or risk factors.

\section{RESULTS}

In the present series of 505 fistulas (baseline characteristics [Table 1]), 185 (36.6\%) were proximal fistulas, $310(61.4 \%)$ were distal fistulas, and $10(2 \%)$ were mid forearm fistulas. Preference was given to nondominant hand. However- in cases where non-dominant hand was pricked repeatedly or had intracath in situ dominant hand was selected. 135 fistulas were done on the right side, and 370 were done on the left side. Basilic vein was used in 133 cases; cephalic vein was used in 321 cases, and antecubital vein was used in 49 cases. Vena comitans and dorsal hand vein were used in 1 case each for anastomosis. Vein anastomosis was done with radial artery in 322 cases and brachial artery in 183 cases. End (vein) to the side (artery) anastomosis was done in 303 cases. Side (vein) to the side (artery) anastomosis was done in 202 cases. Bruit was heard in $459(90.9 \%)$ cases and thrill was felt in 451 (89.3\%) cases on the operation table. Both bruit and thrill were present in 448 cases (88.71\%).

During HD, flow rate $>250 \mathrm{ml} / \mathrm{min}$ was obtained in 150 (29.9\%) cases. It was sufficient to perform successful HD in these patients as it sustained for a period of at least $3 \mathrm{~h}$ during $4 \mathrm{~h}$ of HD. The flow rate $>250 \mathrm{ml} / \mathrm{min}$ was not flow across fistula, as measured by radiological or any other means, but actual flow rate obtained on blood pump during HD.
In complications, $2(0.4 \%)$ patients developed distal oedema, 33 (6.5\%) developed steal phenomenon. One patient developed aneurysm. No patients had operative site infection and major bleeding requiring intervention during the follow-up period.

\section{Logistic regression for success and failure}

Using logistic regression [Table 2] with success and immediate failure as the dependent variables it was found that:

1. Failure is 5.4 times more among subjects with no bruit heard on operation table $(P<0.001)$ as compared to those with bruit.

2. Similarly, failure is 6.7 times more among subjects with no thrill felt on operation table $(P<0.001)$ as compared to those with thrill.

3. Although risk of failure is more among subjects with art $<2 \mathrm{~mm}$ as compared to subjects with art $>2 \mathrm{~mm}$, it is not statistically significant $(P=0.114)$ in our series.

Table 1: Baseline characteristics

\begin{tabular}{|c|c|c|c|c|c|}
\hline \multicolumn{3}{|c|}{ Senario } & \multicolumn{3}{|c|}{ Number } \\
\hline \multicolumn{3}{|c|}{ Number of AVFs created } & \multicolumn{3}{|c|}{505} \\
\hline \multicolumn{3}{|c|}{ Number of patients } & \multicolumn{3}{|c|}{443} \\
\hline \multicolumn{3}{|c|}{ Number of successful AVFs } & \multicolumn{3}{|c|}{$398(78.81 \%)$} \\
\hline \multicolumn{3}{|l|}{ Age } & \multicolumn{3}{|c|}{$54.58( \pm 14.092)$} \\
\hline \multicolumn{6}{|l|}{ Gender } \\
\hline \multicolumn{3}{|l|}{ Male } & \multicolumn{3}{|c|}{$279(62.98 \%)$} \\
\hline \multicolumn{3}{|l|}{ Female } & \multicolumn{3}{|c|}{$164(37.02 \%)$} \\
\hline \multicolumn{3}{|l|}{ Diabetes } & \multicolumn{3}{|c|}{$216(48.76 \%)$} \\
\hline \multicolumn{3}{|c|}{ Atherosclerosis } & \multicolumn{3}{|c|}{$18(4.1 \%)$} \\
\hline Coagulopathy & & & \multicolumn{3}{|c|}{$4(0.9 \%)$} \\
\hline \multicolumn{6}{|c|}{ AVFs: Arteriovenous fistula } \\
\hline \multicolumn{6}{|c|}{ Table 2: Logistic regression table } \\
\hline \multirow{2}{*}{$\begin{array}{l}\text { Variables in } \\
\text { the equation }\end{array}$} & \multirow[t]{2}{*}{ SE } & \multirow[t]{2}{*}{ OR } & \multicolumn{2}{|c|}{$95 \% \mathrm{Cl}$ for OR } & \multirow[t]{2}{*}{$P$ value } \\
\hline & & & Lower limit & Upper limit & \\
\hline \multicolumn{6}{|l|}{ Bruit } \\
\hline Yes & & 1 & & & \\
\hline No & 0.320 & 5.464 & 0.098 & 0.342 & 0.001 \\
\hline \multicolumn{6}{|l|}{ Thrill } \\
\hline Yes & & 1 & & & \\
\hline No & 0.303 & 6.6667 & 0.082 & 0.273 & 0.001 \\
\hline \multicolumn{6}{|l|}{ Vein $<2 \mathrm{~mm}$} \\
\hline Yes & & 1 & & & \\
\hline No & 0.463 & 5.366 & 2.283 & 12.613 & 0.001 \\
\hline \multicolumn{6}{|l|}{ Art $<2 \mathrm{~mm}$} \\
\hline Yes & & 1 & & & \\
\hline No & 0.528 & 2.305 & 0.818 & 6.492 & 0.114 \\
\hline Site of fistula & & & & & \\
\hline Proximal & 0.230 & 1.207 & 0.769 & 1.895 & 0.413 \\
\hline Distal & 1.070 & 0.460 & 0.056 & 3.747 & 0.468 \\
\hline
\end{tabular}


4. Failure is 5.4 times more among patients with vein $<2$ $\mathrm{mm}$ as compared to those with vein $>2 \mathrm{~mm}(P<0.001)$.

5. Risk of failure was observed to be higher among patients with distal fistula $(22.6 \%)$ than proximal fistula (19.5\%), although not statistically significant $(P=0.413)$.

Of 505 fistulas, 449 patients had both presence of bruit and thrill at end of surgery. The failure rate was $16 \%$ $(n=75)$ in such cases at end of 12 weeks. When bruit was present and thrill was absent at the end of the surgery $(n=11)$ the failure rate was $63.6 \%(n=7)$. Only 3 patients had a palpable thrill without an audible bruit. Of these three, one fistula failed (33\%). When both bruit and thrill were absent at the end of the surgery $(n=42)$ the failure rate was as high as $57 \%(n=24)$.

\begin{tabular}{lcc}
\hline Scenario & Number of patients & Failuers (\%) \\
\hline Bruit+, thrill+ & 449 & $75(16)$ \\
Bruit+, thrill- & 011 & $07(63)$ \\
Bruit-, thrill+ & 003 & $01(33)$ \\
Bruit-, thrill- & 042 & $24(57)$ \\
\hline
\end{tabular}

\section{Flow rates}

Patients with vein diam. $>2 \mathrm{~mm}$ had higher flow rates ( $>250 \mathrm{ml} / \mathrm{min}$ ) as compared with patients with vein diam. $<2 \mathrm{~mm}$. The difference was found to be statistically significant $(P=0.05)$.

\section{Diabetes}

1. Flow rates across fistula were found significantly higher in non-diabetic patients $(P<0.001)$ compared to diabetics.

\section{Biochemistry}

The average blood urea and serum creatinine values in patients with successful fistulas were significantly $(P<0.001)$ lower as compared with failures [Table 3].

\section{Site}

1. In proximal fistulas, bruit was heard and thrill was felt in $95.1 \%$ cases on operation table. In distal

fistulas, bruit was heard in $88.1 \%$ and thrill was felt in $85.5 \%$ on operation table. Hence, success rate was more $(80.5 \%)$ in proximal than in distal (77.4\%) fistulas. This difference was however not statistically significant.

2. Of 310 cases of proximal fistulas basilic vein transposition for proximal fistula was done in 1 case only. In rest of the patient's veins over forearm developed within 6 weeks due to retrograde flow across the anastomosis. Distal oedema developed in $2(0.4 \%)$ patients post-operatively.

\section{Mortality}

The incidence of deaths was much higher in cases of primary fistula failure $(60.7 \%)$ as compared with successful fistulas (30.7\%). This value had statistical significance $(P<0.001)$.

\section{Patency $(n=505)$ [Table 4]}

1. Patency more than 1 year was found in 398 cases (78.81\%).

2. Patency more than 2 years was seen in 213 cases (53.63) and

3. Patency more than 3 years was seen in 93 cases (34.39\%).

4. Patency more than 4 years was seen in 36 cases (19.05\%).

5. Patency of more than 5 years was seen in 21 patients (14.81\%).

The data when used for Kaplan - Meier analysis showed the following curve as given in Graph 1.

Table 3: Blood urea and serum creatinine values

\begin{tabular}{lccc}
\hline Biochemistry & Mean & SD & SEM \\
\hline Blood urea level (mg/dl) & & & \\
$\quad$ Successful fistulas & 87.67 & 38.778 & 2.03 \\
$\quad$ Failed fistulas & 112.39 & 38.888 & 4.077 \\
Serum creatinine $(\mathrm{mg} / \mathrm{dl})$ & & & \\
$\quad$ Successful fistulas & 6.022 & 2.0449 & 0.1067 \\
$\quad$ Failed fistulas & 8.608 & 1.7728 & 0.1858 \\
\hline SD: Standard deviation: SEM: Standard error mean & &
\end{tabular}

Table 4: Kaplan-Meier analysis for patency

\begin{tabular}{lcccccc}
\hline Time (in years) & Number of fistulas & Failures & Dropouts & Patency & Probability of patency & Conditional probability of patency \\
\hline 0 & 505 & 0 & & 505 & 1 & 1 \\
1 & 505 & 107 & & 398 & 0.78812 & 0.78812 \\
2 & 313 & 100 & 85 & 213 & 0.68051 & 0.53632 \\
3 & 145 & 52 & 68 & 93 & 0.64138 & 0.34399 \\
4 & 65 & 29 & 28 & 36 & 0.55385 & 0.19052 \\
5 & 27 & 6 & 9 & 21 & 0.77778 & 0.14818 \\
\hline
\end{tabular}




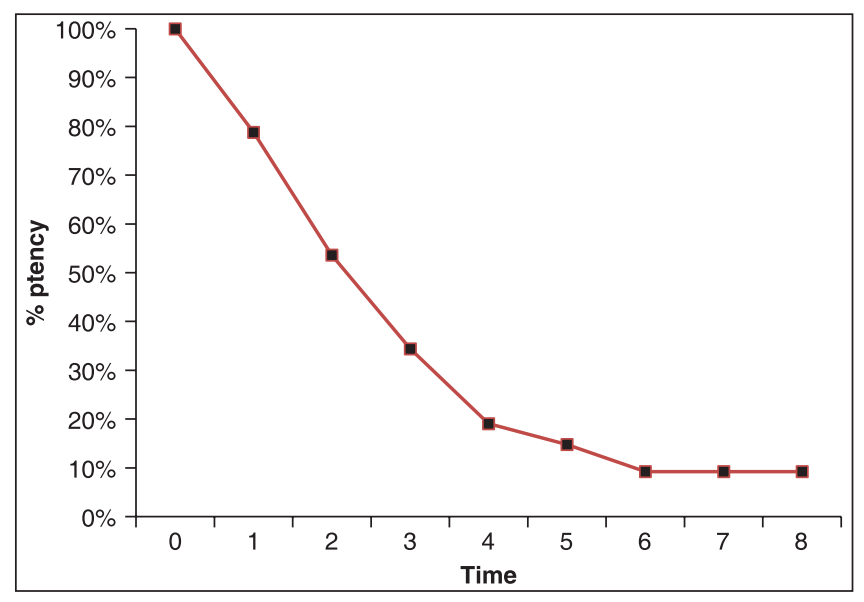

Graph 1: Graph showing Kaplan-Meier analysis for patency

\section{DISCUSSION}

Successful HD depends on creation and maintenance of adequate vascular access. Due to general population aging, median age at onset of ESRD has been progressively increased over last few decades. More than $20 \%$ of people have diabetes as a cause of ESRD and average age is 54.5 years. ${ }^{[4]}$ In our study of 505 cases, average age of presentation was 54.5 years and $48.76 \%$ patients had diabetes as a cause of ESRD.

Patients who receive dialysis across a functional AVF have lower complication rates and longer duration of event-free patency than patients with catheter access ${ }^{|5-8|}$ and arteriovenous grafts (AVGs). ${ }^{[6,9]}$ Thus, construction of a native AVF on arm or forearm is considered a good practice over prosthetic grafts and central venous catheters. There were no AVGs created in the present series. There is vast data proving that native AVFs are superior to grafts as a form of vascular access for dialysis. ${ }^{[6]}$ It has been demonstrated that early referral to nephrologists and good collaboration with microvascular surgeon reduce the need for temporary dialysis access for first dialysis and increase the rate of successful AVF placement. ${ }^{[10]}$ However, central venous catheters are primary method of choice for temporary access in which there is urgent need for HD and no other vascular access is available or has failed. ${ }^{[8]}$ However, these devices suffer from several complicating factors as infection, thrombosis, venous stenosis, and damage to proximal vessels. ${ }^{[11]}$ We performed AVF in all our chronic kidney disease patients as first choice of vascular access.

The most common operative procedure was the creation of the distal radio-cephalic fistula, initially described by
Brescia et al. in 1966..$^{[1]}$ This operation is still considered to be the gold standard for vascular access for $\mathrm{HD}^{[12]}$ and it accounted for $310(61.4 \%)$ of our operative procedures. High radio-cephalic (mid forearm) and brachial-basilic AVFs were reserved for patients with previously failed Brescia-Cimino AVFs or where patent adequate size vessels at wrist level were not available for anastomosis. The outcomes of the classic Brescia-Cimino operation were accompanied by acceptable rates of morbidity. ${ }^{[13,14]}$ In our analysis of $310(61.4 \%)$ distal fistulas, 240 (77.42\%) were successful. 2 patients developed distal oedema $(0.65 \%)$ and 16 patients developed steal phenomenon (5.16\%). Mortality among cases with radio-cephalic fistulas was 114 (36.77\%).

Most large-volume centres report $15-30 \%$ primary failure rates for distal radio-cephalic AVF. ${ }^{[13,14]}$ The reported incidence of primary failure in the medical literature varies from $9 \%^{[15]}$ to $40 \%[16]$ and our results with $21.2 \%$ primary failures were comparable. Primary Failure is defined as Absence of well-developed veins accessible for dialysis at 12 weeks after fistula surgery. ${ }^{[16]}$ The NKF/ DOQI work Group did not recommend the use of primary failure as an index of quality because it would discourage attempts at AVF construction in patients with complex vascular anatomy. ${ }^{[2]}$

American Institute of Ultrasound in Medicine Practice Guideline $2011^{[17,18]}$ states that arterial diameter $<2 \mathrm{~mm}$ and venous diameter $<2.5 \mathrm{~mm}$ were associated with high failure rate. This study also proves that venous diameters $<2 \mathrm{~mm}$ are associated with significantly high failure rates $(P<0.001)$. However, arterial diameter of $<2 \mathrm{~mm}$ was not found to be significant in our series.

Arteriovenous fistula creation in all (100\%) patients with ESRD in our institution far exceeds the target goals of $50 \%$ set forward by the NKF/DOQI ${ }^{[3]}$ and the Centres for Medicare and Medicaid Services Fistula First Breakthrough Initiative. ${ }^{[19]}$ This was being achieved with acceptable rates of morbidity (7.2\%), no operative mortality and good primary patency (78\%). However, early detection of complications by patient education can help to improve long-term patency rates.

Results of Kazemzadeh et al..$^{[20]}$ in 2012, in their case series of 245 patients of primary patency at 6 months, 1 , 2,3 , and 4 years for 245 patients were $79.5 \%, 70 \%, 65 \%$, $60.5 \%$, and $48 \%$, respectively. This was comparable to our results showing $78.81 \%$ patency of fistulas at the end of 
1 year. However, in our series patency rates dropped to, $53.63 \%$ patency at the end of 2 years, 34.39 patency at the end of 3 years, 19.05 patency at the end of 4 years, 14.81 patency at the end of 5 years. Our primary failure rate was $21.18 \%$.

It is routine practice to transpose basilic vein during proximal brachiobasilic fistulas ${ }^{[2]}$ In a series of 70 patients with brachiobasilic fistulas in order to gain easy access to veins, Hossny ${ }^{[2]}$ observed that all dialysis nurses were satisfied with the transposed veins, but only $53.3 \%$ were satisfied with the elevated veins; the difference was statistically highly significant $(P<0.001)$. Thus, concluding that among the various procedures, transposition has a lower complication rate and is favoured by the dialysis staff dealing with such fistulas. In our study, during the creation of proximal fistula by side-to-side anastomosis between antecubital/ basilic vein and brachial artery, dilatation of distal vein to dysfunction the first valve towards wrist end helps to develop distal veins in the forearm by retrograde flow avoiding need for transposition of basilic vein thus avoiding the additional extensive procedure of transposition. In only one of our patients with proximal fistula superficialization of basilic vein in the arm was needed. Distal oedema was seen only in 2 patients with proximal fistula.

Though the risk of failure was observed to be lower in proximal fistulas in our series, it was not statistically significant. In a study conducted by Sultan et al. ${ }^{[23]}$ it was observed that 4 years primary functional patency was better with proximal fistula as compared with distal fistulas.

We have established direct correlation of bruit heard at end of surgery and thrill felt at the end of the surgery with the final outcome of the fistula. In the majority of our cases, we had both present at the end of the surgery (449 out of 505). In cases where both were absent the failure rate was as high as $57 \%$. Since the failure is defined as the absence of visible veins suitable for cannulation at the end of 12 weeks after surgery, we have to wait for veins to develop until at least 12 weeks. In cases where either bruit or thrill or both were absent at the end of surgery, we started patient on anticoagulative measures as described earlier along with handball exercises. No surgical intervention was done in any of the cases with absent bruit and/or thrill. In India, because of poor socioeconomic status, fistula salvage by early detection of failing fistula and intervention by exploration, embolectomy, or radiological intervention like percutaneous angioplasty for venous outflow stenosis $^{[3]}$ is not cost-effective. In our study, no salvage or secondary procedures were done and hence all our statistics reflect primary failures. We prefer to perform new fistula in cases where previous has failed or not sustaining adequate flow rates on HD.

\section{CONCLUSION}

We found that

1. Vein diameter $<2 \mathrm{~mm}$. showed very high failure rate $(P<0.001)$. Hence, we recommend either using proximal site or use of the alternative method of access placement such as peritoneal dialysis/permacaths in such patients.

2. Thrill felt on the operation table has a direct relation with success of fistula operation $(P<0.001)$.

3. Similarly, presence of on table bruit was found to be statistically significant in correlation with success of fistula surgery $(P<0.001)$.

4. Flow rates in patients with vein diameter $>2 \mathrm{~mm}$ were significantly higher as compared with patients with vein diameter $<2 \mathrm{~mm}(P<0.001)$.

5. Flow rates are higher in non-diabetic patients as compared with diabetic patients $(P<0.001)$.

6. Average blood urea and serum creatinine values are significantly lesser in patients undergoing dialysis through successful fistulas as compared with patients with failed fistulas. Correspondingly, incidence of deaths is significantly lesser in patients with successful fistulas $(P<0.001)$.

7. During the creation of proximal fistula by side-to-side anastomosis between antecubital/basilic vein and brachial artery, dilatation of distal vein to dysfunction the first valve towards wrist helps to develop distal veins in the forearm by retrograde flow avoiding need for basilic vein transposition.

8. Primary patency rates by Kaplan-Meier analysis shows $78.81 \%$ patency of fistulas at the end of 1 year, 53.63 patency at the end of 2 years, 34.39 patency at the end of 3 years, $19.05 \%$ patency at the end of 4 years, 14.81 patency at the end of 5 years.

The presence of Bruit and thrill on the operation table at the end of the surgery are the key indicators of successful fistula. This has not been reported in the literature so far to the best of our knowledge. 


\section{ACKNOWLEDGEMENTS}

The author would like to thank Consultants of Department of Medicine, Consultants and staff of Department of Nephrology, Dr. Kanade Asawari, Department of Research Deenanath Mangeshkar Hospital, Pune. Prof. Mukund Thatte Consultant Plastic Surgeon, Mumbai.

\section{REFERENCES}

1. Brescia MJ, Cimino JE, Appel K, Hurwich BJ. Chronic hemodialysis using venipuncture and a surgically created arteriovenous fistula. N Engl J Med 1966;275:1089-92.

2. Levey AS, Coresh J, Greene T, Marsh J, Stevens LA, Kusek JW, et al. Expressing the modification of diet in renal disease study equation for estimating glomerular filtration rate with standardized serum creatinine values. Clin Chem 2007;53:766-72.

3. III. NKF-K/DOQI clinical practice guidelines for vascular access: Update 2000. Am J Kidney Dis 2001;37 (1 Suppl):S137-81.

4. Konner K. Primary vascular access in diabetic patients: An audit. Nephrol Dial Transplant 2000;15:1317-25.

5. Tordoir JH, Van Der Sande FM, De Haan MW. Current topics on vascular access for hemodialysis. Minerva Urol Nefrol 2004;56:223-35.

6. Young EW, Dykstra DM, Goodkin DA, Mapes DL, Wolfe RA, Held PJ. Hemodialysis vascular access preferences and outcomes in the dialysis outcomes and practice patterns study (DOPPS). Kidney Int 2002;61:2266-71.

7. van Andringa de Kempenaer T, ten Have P, Oskam J. Improving quality of vascular access care for hemodialysis patients. Jt Comm J Qual Saf 2003;29:191-8.

8. Kong NC, Morad Z, Suleiman AB. Subclavian catheters as temporary vascular access. Singapore Med J 1989;30:261-2.

9. Roy-Chaudhury P, Kelly BS, Melhem M, Zhang J, Li J, Desai P, et al. Vascular access in hemodialysis: Issues, management, and emerging concepts. Cardiol Clin 2005;23:249-73.

10. Chesser AM, Baker LR. Temporary vascular access for first dialysis is common, undesirable and usually avoidable. Clin Nephrol 1999;51:228-32.

11. Weiswasser JM, Kellicut D, Arora S, Sidawy AN. Strategies of arteriovenous dialysis access. Semin Vasc Surg 2004;17:10-8.

12. Malovrh M. Approach to patients with end-stage renal disease who need an arteriovenous fistula. Nephrol Dial Transplant 2003;18 Suppl 5:V50-2.

13. Haimov M, Baez A, Neff M, Slifkin R. Complications of arteriovenous fistulas for hemodialysis. Arch Surg 1975;110: 708-12.

14. Al Shohaib S, Al Sayyari A, Waness AA. Hemodialysis angioaccess choice and survival in a tertiary care Saudi Arabian center from 1993 to 2004. Nephrourol Mon 2011;3:69-73.

15. Bakari AA, Nwankwo EA, Yahaya SJ, Mubi BM, Tahir BM. Initial five years of arterio-venous fistula creation for hemodialysis vascular access in Maiduguri, Nigeria. Internet J Cardiovasc Res 2007;4:1-6.

16. Huijbregts $\mathrm{HJ}$, Bots $\mathrm{ML}$, Wittens $\mathrm{CH}$, Schrama $\mathrm{YC}$, Moll FL, Blankestijn $\mathrm{PJ}$, et al. Hemodialysis arteriovenous fistula patency revisited: Results of a prospective, multicenter initiative. Clin $J$ Am Soc Nephrol 2008;3:714-9.

17. Silva MB Jr, Hobson RW $2^{\text {nd }}$, Pappas PJ, Jamil Z, Araki CT, Goldberg MC, et al. A strategy for increasing use of autogenous hemodialysis access procedures: Impact of preoperative noninvasive evaluation. J Vasc Surg 1998;27:302-7.

18. American College of Radiology (ACR). American Institute of Ultrasound in Medicine (AIUM), Society of Radiologists in Ultrasound (SRU). ACR-AIUM-SRU Practice Guideline for the Performance of Peripheral Arterial Ultrasound using Color and Spectral Doppler. Reston (VA): American College of Radiology (ACR); 2010. p. 5.

19. Lok CE. Fistula first initiative: Advantages and pitfalls. Clin J Am Soc Nephrol 2007;2:1043-53.

20. Kazemzadeh GH, Modaghegh MH, Ravari H, Daliri M, Hoseini L, Nateghi M. Primary patency rate of native AV fistula: Long term follow up. Int J Clin Exp Med 2012;5:173-8.

21. Beathard GA. Fistula First National Vascular Access Improvement Initiative - A Practioners's Resource Guide to Hemodialysis Arteriovenous Fistulas - ESRD Network 13, 2004. Available from: http://www.esrdnet15.org/QI/C5E.pdf. [Last accessed on 2013 Jul 11].

22. Hossny A. Brachiobasilic arteriovenous fistula: Different surgical techniques and their effects on fistula patency and dialysisrelated complications. J Vasc Surg 2003;37:821-6.

23. Sultan S, Hynes N, Hamada N, Tawfick W. Patients on hemodialysis are better served by a proximal arteriovenous fistula for long-term venous access. Vasc Endovascular Surg 2012;46:624-34.

How to cite this article: Sahasrabudhe P, Dighe T, Panse N, Deshpande S, Jadhav A, Londhe S. Prospective long-term study of patency and outcomes of 505 arteriovenous fistulas in patients with chronic renal failure: Authors experience and review of literature. Indian J Plast Surg 2014;47:362-9.

Source of Support: Nil, Conflict of Interest: None declared.

Announcement

\section{$6^{\text {TH }}$ AND $10^{\text {TH }}$ OF JULY, 2015}

\section{IPRAS 2015 - $18^{\text {th }}$ IPRAS World Congress}

Venue: Hofburg Palace, Vienna, Austria

Contact: Mr. Nikos Antonopoulos

Telephone: (+30) 211-1001782

Fax: $(+30)$ 210-6642116

E-mail: n.an@zita-congress.gr

URL: http://www.ipras2015.com 